\title{
miRNAome analysis of the mammalian neuronal nicotinic acetylcholine receptor gene family
}

\author{
ERIC M. HOGAN, ${ }^{1,2,4}$ ALISON P. CASSERLY, ${ }^{1,3}$ MICHAEL D. SCOFIELD, ${ }^{1,2,5}$ ZHONGMING MOU, ${ }^{1}$ \\ RUBING ZHAO-SHEA, ${ }^{1}$ CHRIS W. JOHNSON, ${ }^{1}$ ANDREW R. TAPPER, ${ }^{1,2,3}$ and PAUL D. GARDNER ${ }^{1,2,3}$ \\ ${ }^{1}$ Brudnick Neuropsychiatric Research Institute, Department of Psychiatry, ${ }^{2}$ Interdisciplinary Graduate Program, \\ ${ }^{3}$ UMMS MD/PhD Program, University of Massachusetts Medical School, Worcester, Massachusetts 01604, USA
}

\begin{abstract}
Nicotine binds to and activates a family of ligand-gated ion channels, neuronal nicotinic acetylcholine receptors (nAChRs). Chronic nicotine exposure alters the expression of various nAChR subtypes, which likely contributes to nicotine dependence; however, the underlying mechanisms regulating these changes remain unclear. A growing body of evidence indicates that microRNAs (miRNAs) may be involved in nAChR regulation. Using bioinformatics, miRNA library screening, site-directed mutagenesis, and gene expression analysis, we have identified a limited number of miRNAs that functionally interact with the $3^{\prime}$-untranslated regions ( $3^{\prime}$ UTRs) of mammalian neuronal nAChR subunit genes. In silico analyses revealed specific, evolutionarily conserved sites within the $3^{\prime}$ UTRs through which the miRNAs regulate gene expression. Mutating these sites disrupted miRNA regulation confirming the in silico predictions. In addition, the miRNAs that target nAChR $3^{\prime}$ UTRs are expressed in mouse brain and are regulated by chronic nicotine exposure. Furthermore, we show that expression of one of these miRNAs, miR-542-3p, is modulated by nicotine within the mesocorticolimbic reward pathway. Importantly, overexpression of miR-542-3p led to a decrease in the protein levels of its target, the nAChR $\beta 2$ subunit. Bioinformatic analysis suggests that a number of the miRNAs play a general role in regulating cholinergic signaling. Our results provide evidence for a novel mode of nicotine-mediated regulation of the mammalian $\mathrm{nAChR}$ gene family.
\end{abstract}

Keywords: nicotinic acetylcholine receptor; miRNA analysis; gene expression; miR-542-3p

\section{INTRODUCTION}

Despite considerable educational and legislative efforts, tobacco use remains the single most avoidable cause of death in the world (WHO 2009). At the molecular level, nicotine, the addictive component of tobacco, initiates dependence by binding to and activating neuronal nicotinic acetylcholine receptors ( $\mathrm{AAChRs),} \mathrm{which} \mathrm{are} \mathrm{normally} \mathrm{activated} \mathrm{by} \mathrm{the}$ endogenous neurotransmitter acetylcholine (ACh) (Albuquerque et al. 2009; Improgo et al. 2010). Activation of the receptors in the dopaminergic mesocorticolimbic reward pathway is thought to underlie the initiation of dependence whereas signaling through $\mathrm{nAChRs}$ in the habenulo-interpeduncular pathway that feeds into the reward pathway is thought to play a key role in eliciting nicotine-associated withdrawal symptoms (Albuquerque et al. 2009; Salas et al. 2009; Zhao-Shea et al. 2013). Neuronal nAChRs are a family of ligand-gated cation channels signaling through which

\footnotetext{
${ }^{4}$ Deceased

${ }^{5}$ Present address: Department of Neurosciences, Medical University of South Carolina, Charleston, SC 29425, USA

Corresponding author: paul.gardner@umassmed.edu

Article published online ahead of print. Article and publication date are at http://www.rnajournal.org/cgi/doi/10.1261/rna.034066.112.
}

underlies a variety of fundamental physiological processes (Dani 1993, 2001). To date, 11 distinct mammalian neuronal nAChR subunits have been identified ( $\alpha 2-\alpha 7, \alpha 9, \alpha 10$, and $\beta 2-\beta 4)$. Five subunits coassemble to form functional receptors with the subunit composition defining the pharmacological and biophysical properties of each nAChR subtype (Corringer et al. 2000). Heteromeric nAChRs, consisting of two or three a subunits and two or three $\beta$ subunits, have high affinities (nanomolar concentrations) for nicotine whereas homomeric nAChRs, the predominant subtype containing a7 subunits, have relatively low affinities ( $\mu \mathrm{M}$ concentrations) for nicotine (Cooper et al. 1991; McGehee and Role 1995; Leonard and Bertrand 2001). Given there are 11 members of the $\mathrm{nAChR}$ subunit family, the potential for a substantial variety of functionally distinct $\mathrm{nAChR}$ subtypes exists. This functional diversity is a consequence of the molecular mechanisms that dictate the availability of nAChR subunits in the appropriate cellular contexts and

\footnotetext{
(C) 2014 Hogan et al. This article is distributed exclusively by the RNA Society for the first 12 months after the full-issue publication date (see http://rnajournal.cshlp.org/site/misc/terms.xhtml). After 12 months, it is available under a Creative Commons License (Attribution-NonCommercial 4.0 International), as described at http://creativecommons.org/licenses/ by-nc/4.0/.
} 
the appropriate developmental stages. While a substantial effort has been put forth to understand these mechanisms (Albuquerque et al. 2009), they remain to be completely elucidated.

In addition to activating nAChRs, nicotine also causes an increase in high affinity nicotine-binding sites following chronic exposure (Marks et al. 1983; Benwell et al. 1988; Flores et al. 1992); however, the underlying mechanisms leading to the up-regulation remain unclear, although transcriptional mechanisms are not thought to be involved (Marks et al. 1992). Regardless, all models must account for a change in the levels of available nAChR protein leading to changes in the biophysical and ligand-binding properties of the receptors (Albuquerque et al. 2009; Govind et al. 2009). Several levels of regulation underlying nicotine-induced changes in nAChR subtypes could potentially exist. These include changes in receptor protein levels, assembly, conformation, stoichiometry, and/or turnover. Evidence exists for all of these (Peng et al. 1994; Nashmi et al. 2003; Nelson et al. 2003; Darsow et al. 2005; Ficklin et al. 2005; Sallette et al. 2005; Vallejo et al. 2005; Moroni et al. 2006; Rezvani et al. 2007; Walsh et al. 2008; Govind et al. 2009, 2012; Srinivasan et al. 2011; Columbo et al. 2013), supporting the idea that it is not likely that any single mechanism exclusively accounts for all the observed changes in nAChR subtype expression during or after chronic nicotine exposure.

A growing body of evidence indicates that nicotine and cigarette smoke alter the expression of small 21-24-nt long regulatory molecules referred to as microRNAs (miRNAs). miRNAs are predicted to regulate the majority of all mammalian protein coding genes (Friedman et al. 2009; Ghildiyal and Zamore 2009; Ameres and Zamore 2013). These regulatory molecules are particularly abundant in the brain and play important roles in several aspects of nervous system development (Cao et al. 2006; Bicker and Schratt 2008; Fiore et al. 2008). miRNAs typically function by guiding a target mRNA to an RNA-induced silencing complex (RISC), which causes either inhibition of translation or mRNA degradation (Friedman et al. 2009; Ghildiyal and Zamore 2009). However, miRNAs can also cause an increase in target gene expression (Vasudevan et al. 2007). Interestingly, miRNAs are regulated by nicotine and/or tobacco smoke in several tissues and cell lines. For example, Balaraman et al. (2012) demonstrated that treatment of cerebral cortical-derived neurospheres with nicotine, at concentrations similar to those attained by cigarette smokers, induced a dose-related increase in the expression of several miRNAs, an effect that is blocked by the nonselective nAChR antagonist, mecamylamine. Interestingly, given the comorbidity of nicotine dependence and alcohol abuse, three of the miRNAs regulated by nicotine are also ethanol-sensitive (Balaraman et al. 2012). In another study, miRNA analysis of airway epithelium of smokers compared with nonsmokers demonstrated significant differences in miRNA expression (Schembri et al. 2009). The lungs of rats exposed to cigarette smoke displayed a change in expres- sion of 126 miRNAs (Izzotti et al. 2009). In addition, nicotine alters miRNA expression levels in canine atrial fibroblasts (Shan et al. 2009) and a rat pheochromocytoma cell line, PC12 (Huang and Li 2008). Furthermore, a recent study demonstrated regulation of miRNA expression by nicotine in adult mouse brain (Lippi et al. 2011). With respect to nAChR expression, it has been demonstrated that miR-1 regulates translation of two nAChR subunits, UNC-29 and UNC-63, in the body muscles of Caenorhabditis elegans, which leads to changes in the functional properties of the mature nAChR receptors (Simon et al. 2008). More recently, Gallego et al. (2013) showed that over-expression of miR138 down-regulated reporter gene expression in constructs containing the nAChR $\beta 4$ subunit $3^{\prime}$-untranslated region ( $3^{\prime}$ UTR) that includes a potential miR-138-binding site. To the best of our knowledge, however, there are no reports demonstrating the role of miRNAs in regulating endogenous mammalian neuronal nAChR expression.

Here, we report a miRNAome analysis of the mammalian neuronal nAChR family. We demonstrate that a subset of miRNAs regulates gene expression via functional interactions with miRNA recognition elements (MREs) in the $3^{\prime}$ UTRs of mammalian nAChR receptor subunit genes. Furthermore, we show that several of these miRNAs are regulated by chronic nicotine exposure in the mammalian brain. Finally, we demonstrate that overexpression of one of the miRNAs, miR-542-3p, led to a decrease in the protein levels of its target, the nAChR $\beta 2$ subunit. Our findings provide evidence for a novel mode of $\mathrm{nAChR}$ regulation that is likely to be relevant to the molecular underpinnings of nicotine-associated behaviors.

\section{RESULTS AND DISCUSSION}

\section{A miRNA library screen identifies a limited number of miRNAs as potential regulators of $n A C h R$ expression}

Using three algorithms, Targetscan (Lewis et al. 2005), Microcosm Targets (Griffiths-Jones et al. 2008), and miRDIP (Shirdel et al. 2011), we detected a large number of potential MREs for a wide variety of miRNAs in the $3^{\prime}$ UTRs of the 11 mammalian neuronal nAChR subunit genes (data not shown). To systematically investigate whether any of these miRNAs may regulate gene expression via interactions with the nAChR 3' UTRs, we performed a large-scale in vitro screen wherein we coexpressed, in HEK293T cells, luciferase reporter constructs containing each nAChR subunit $3^{\prime}$ UTR with each miRNA precursor mimic from a mouse miRNA precursor library (see Materials and Methods for details). As expected, the majority of miRNAs coexpressed with the luciferase/nAChR constructs did not alter reporter gene activity (Supplemental Fig. 1). Interestingly, however, a limited number of miRNAs did affect expression of the luciferase/ nAChR 3'-UTR constructs. A subset of miRNAs caused 
significant decreases in luciferase activity while another gave rise to significant increases in luciferase activity (Supplemental Fig. 1). The changes in luciferase activity ranged from a $\sim 60 \%$ decrease to a $\sim 80 \%$ increase. We focused on those miRNAs that led to a significant repression of luciferase activity as that is the primary mode of regulation by most miRNAs (Ambros 2004; Bartel 2009; Thomas et al. 2010). We have not pursued the miRNAs that increased luciferase activity. A secondary screen was carried out to confirm the results of the primary screen and identified 27 miRNAs that down-regulated luciferase/nAChR expression (Supplemental Table 1).

\section{Site-directed mutagenesis of $\mathrm{nACh}$ subunit $3^{\prime}$-UTR miRNA binding sites}

miRNAs regulate gene expression via interactions with MREs and can function in a combinatorial manner if an mRNA transcript contains multiple MREs (Salmena et al. 2011). Using TargetScan, Microcosm Targets, and miRDIP, we identified 249 potential MREs in the nAChR 3' UTRs representing potential binding sites for all 27 miRNAs that came through the miRNAome screen (Supplemental Table 1). The majority of these MREs (223), however, are present in nAChR 3' UTRs that did not, in the HEK293T system, functionally interact with the corresponding miRNAs (Supplemental Table 1, $\square$ ). It is possible that such miRNAs may regulate $\mathrm{nAChR}$ expression in a different cellular context. For the remaining 26 potential MREs, site-directed mutagenesis was performed to determine whether any of them are necessary for miRNA regulation in our system. As shown in Figure 1 and Supplemental Table $1(\otimes)$, mutation of 16 of the 26 MREs resulted in derepression of miRNA regulation of luciferase activity. In one case, nAChR a6/miR-7a, mutation of two MREs was necessary for derepression (Fig. 1). In nine cases, mutation of an MRE had no effect on miRNA regulation of the luciferase/ nAChR 3'-UTR constructs (Supplemental Table $1, \nabla)$. In summary, we identified 27 miRNAs that regulate expression of luciferase/nAChR 3 '-UTR reporter constructs with 14 of these miRNAs requiring an intact MRE to exert their regulatory effects. Finally, there were nine cases representing eight miRNAs in which miRNA regulation was seen but for which no MREs were identified in the nAChR 3' UTRs (Supplemental Table 1, checkmarks) possibly indicating that the miRNAs regulate gene expression indirectly or that they bind to as yet unidentified MREs.

\section{Conservation of MREs between human and mouse nAChR 3' UTRs}

Among the 14 mouse miRNAs that functioned via canonical MREs in the luciferase/nAChR 3'-UTR experiments presented in Figure 1, 10 have human homologs (miR-494, miR-346, miR-491, miR-7a, miR-208, miR-490-3p, miR542-3p, miR297b, miR-374-3p, and miR-668) while four do not (miR-667, miR-688, miR-698, and miR-704). We used miRbase to investigate whether any of the latter four miRNAs have human orthologs. Three of them, miR-688, miR-698, and miR-704, do not, however, rodent miR-667 is homologous to human miR-766.

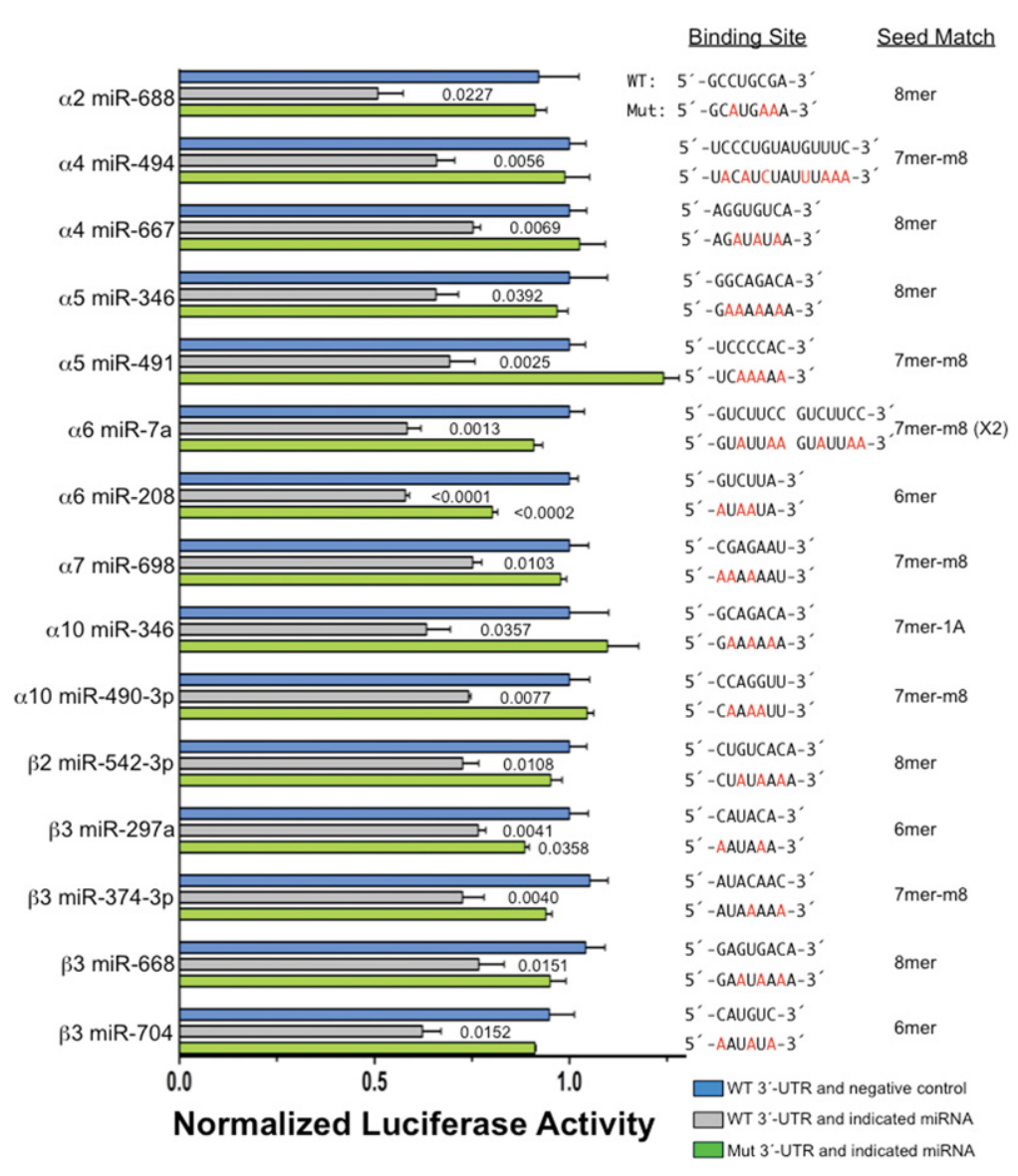

FIGURE 1. miRNAs act through predicted MREs in the nAChR $3^{\prime}$ UTRs. Predicted MREs in the indicated nAChR $3^{\prime}$ UTRs were disrupted via site-directed mutagenesis (mutated nucleotides are shown in red) and assayed for miRNA-mediated repression of luciferase activity as described in Supplemental Figure S1. Each bar represents the normalized luciferase activity assayed from HEK293T cells transfected with the indicated luciferase/nAChR $3^{\prime}$-UTR construct and a miRNA precursor mimic, or negative control miRNA precursor mimic $(n=3-6)$. Data are presented as mean \pm SEM. $P$-values compared with a negative miRNA control derived from the Student's $t$-test are indicated. The types of seed match sites (binding sites corresponding to the miRNA seed region) are indicated. 
With respect to the nAChR subunits, we found MREs for miR-7a, miR-491, miR-494, miR-542-3p, miR-668, and miR-766 in human nAChR subunit 3' UTRs (Fig. 2). Interestingly, there are five miR-491 MREs in the $\beta 23^{\prime}$ UTR and two miR-668 MREs in the a4 3' UTR (Fig. 2). The significance of multiple MREs for a given miRNA in a human nAChR $3^{\prime}$ UTR remains to be determined but may be reminiscent of mouse $\mathrm{miR}-7 \mathrm{a}$ regulation of the luciferase/nAChR a6 3'-UTR construct in which both miR-7a MREs had to be mutated in order for derepression to be observed (Fig. 1). Using Multiple Sequences Alignment (MUSCLE), we identified three miRNAs, miR-494, miR542-3p, and miR-667/766 that have conserved MREs in the corresponding mouse and human nAChR subunit $3^{\prime}$ UTRs. Specifically, the mouse and human a4 nAChR subunit $3^{\prime}$ UTRs both share seed match sites for miR-494 and miR$667 / 766$, whereas the mouse and human $\beta 2 \mathrm{nAChR}$ subunit 3' UTRs both share seed match sites for miR-542-3p (data not shown), which, as shown below, regulates endogenous $\beta 2$ subunit expression. Conservation of MREs in the $\alpha 4$ and $\beta 2$ subunits is particularly intriguing as these two subunits co-assemble to form the predominant nicotine high-affinity nAChR subtype expressed in the brain and as such, is a common target for smoking cessation drug discovery (e.g., varenicline, Coe et al. 2005). The MREs for the other three miRNAs (miR-7a, miR-491, and miR-668) are present in dif-

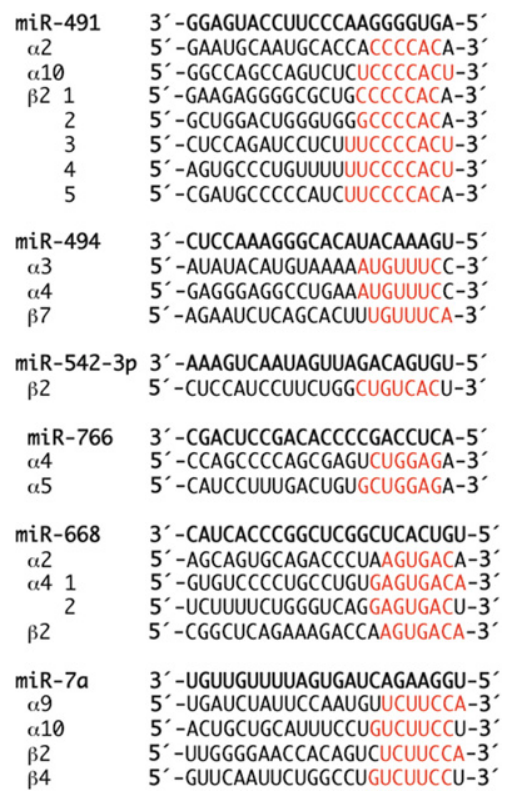

FIGURE 2. MREs in human nAChR subunit $3^{\prime}$ UTRs. Six of the miRNAs that were determined from the large-scale screen to regulate mouse nAChR 3' UTRs (Fig. 1, Supplemental Table 1) have potential MREs in several human nAChR subunit $3^{\prime}$ UTRs. The six miRNAs are indicated in bold. The seed match site in each human nAChR subunit $3^{\prime}$ UTR is shown in red and is aligned to the seed region of the miRNA. In the case where a $3^{\prime}$ UTR has multiple predicted MREs, each site is designated by a number in order of location moving in a $5^{\prime}-3^{\prime}$ direction. ferent nAChR 3' UTRs in humans as compared with mouse. That is to say, miR-7a MREs are found in human nAChR $\alpha 9$, $\alpha 10, \beta 2$, and $\beta 43^{\prime}$ UTRs, where in mouse it is present in the a6 3' UTR. miR-491 MREs are present in human nAChR a2, $\alpha 10$, and $\beta 23^{\prime}$ UTRs, where in mouse the miR-491 MRE is present in the a5 $3^{\prime}$ UTR. miR-668 MREs are found in human nAChR a2, $\alpha 4$, and $\beta 23^{\prime}$ UTRs while in mouse it is seen in the $\beta 33^{\prime}$ UTR.

We were intrigued by the conservation of miR-494, miR542-3p, and miR-667/766 MREs in the corresponding mouse and human nAChR $3^{\prime}$ UTRs and asked whether genes encoding other components of the cholinergic signaling pathway contain similarly conserved MREs in their 3' UTRs. Rather interestingly, a Targetscan analysis revealed the presence of miR-494, miR-542-3p and miR-667/766 MREs in a variety of mouse and human genes encoding a number of key players in cholinergic signaling including choline transporters, cholinesterases and $\mathrm{nAChR}$ subunit chaperone proteins (Supplemental Table 2). The physiological significance of these MREs awaits further study but their presence supports a hypothesis in which a limited number of miRNAs coordinately regulate a family of genes whose products work together to effect cholinergic signaling and may suggest novel drug targets for pathologies in which cholinergic signaling is compromised.

\section{miRNA expression analysis}

The miRNAome analysis presented above identified 27 miRNAs that down-regulated luciferase/nAChR expression in HEK293T cells (Supplemental Fig. S1 and Supplemental Table 1) leading to the hypothesis that these miRNAs regulate nAChR expression in the brain. Consistent with this hypothesis, quantitative reverse-transcription-PCR (qRT-PCR) was used to demonstrate expression of the miRNAs in the brain with the exception of miR-208 and miR-374-3p, which were not detected at all (data not shown). It is possible that miR-208 and miR-374-3p regulate $\mathrm{nAChR}$ expression in other tissues as the nAChR family is known to be expressed throughout the body (Albuquerque et al. 2009).

A logical extension of the hypothesis just presented is that the candidate miRNAs regulate neuronal $\mathrm{nAChR}$ expression in response to nicotine treatment. It follows, then, that the miRNAs themselves are regulated by nicotine and further, if miRNA regulation plays a role in the well documented nicotine-induced up-regulation of nAChRs, presumably miRNA expression would be down-regulated by nicotine. To test this idea, mice were chronically treated with nicotine or saline followed by miRNA expression analysis. Nicotine induced a general trend of miRNA down-regulation among the majority of the miRNAs analyzed, consistent with a role in nicotine-induced $\mathrm{nAChR}$ up-regulation (Supplemental Fig. 2). Statistically significant decreases in expression in mice chronically treated with nicotine, as compared with saline-treated controls, were observed for seven miRNAs: miR- 
200c, miR-201, miR-24, miR-422b, miR-490, miR-491, and miR-704. In one case, miR-688, there was an apparent increase in expression but this did not reach statistical significance. The mechanism by which nicotine alters miRNA expression is unknown but presumably could occur at several levels of miRNA biogenesis such as transcription, nuclear processing, or RISC formation. In addition, nicotine may change miRNA tailing, editing, methylation, or stability leading to effects on miRNA expression (Ha and Kim 2014).

\section{miRNA and nAChR expression in the reward pathway}

The data presented in Supplemental Figure 2 were generated from whole brains. In order to gain more insight as to the potential role miRNAs may play in nicotine-mediated regulation of $\mathrm{nAChR}$ expression, we determined the expression levels of two miRNAs, miR-494, and miR-542-3p, and their predicted targets, the $\alpha 4$ and $\beta 2$ nAChR mRNAs, respectively (see Fig. 1), within specific regions of the mesocorticolimbic reward circuitry. These two nAChR subunits are of particular interest because first, most of the high-affinity nAChRs expressed within the reward pathway contain the $\alpha 4$ and $\beta 2$ subunits (Zhao-Shea et al. 2011) and second, both subunits have been shown to be critical for nicotine-dependence associated behaviors (Picciotto et al. 1998; Tapper et al. 2004). As shown in Figure 3, miR-494 expression was not altered by chronic nicotine treatment in any of the regions tested, the nucleus accumbens (NAc), the prefrontal cortex (PFC), or the ventral tegmental area (VTA). Similarly, a4 nAChR mRNA expression was not significantly changed following nicotine treatment (Fig. 3). Interestingly, however, there appears to be a reciprocal relationship between miR-542-3p and $\beta 2 \mathrm{nAChR}$ mRNA expression levels following chronic nicotine treatment. In the VTA, miR-542-3p expression was significantly decreased by nicotine whereas $\beta 2$ expression was significantly up-regulated (Fig. 3). $\beta 2$ expression was also significantly increased by nicotine in the NAc and PFC, however, miR-542-3p expression, while trending in a downward manner, was not significantly different (Fig. 3). Together, these data support the contention that miRNAs may contribute to nicotine-mediated up-regulation of $\mathrm{nAChR}$ expression.

\section{miRNA regulation of endogenous $\mathrm{nACh}$ expression}

The experiments presented above demonstrate that a subset of miRNAs down-regulate $\mathrm{nAChR}$ mRNA expression. It is important to determine if this effect extends to $\mathrm{nAChR}$ protein expression given the functional implications of such regulation. To address this critical issue, we used the rat pheochromocytoma cell line, PC12, which expresses relatively high levels of nAChR subunits following nerve growth factor treatment (Henderson et al. 1994). PC12 cells were transfected with either miR-542-3p mimic or inhibitor followed by $3 \mathrm{~d}$ of nerve growth factor treatment and sub-
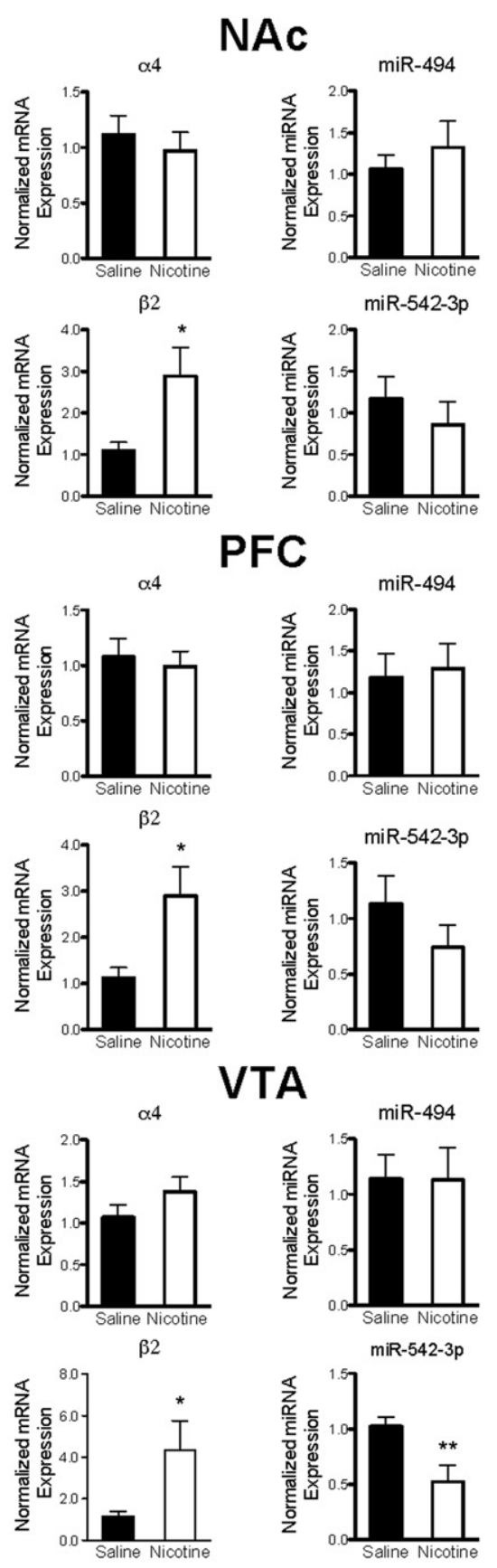

FIGURE 3. Reciprocal relationship between miR-542-3p and nAChR $\beta 2$ transcript levels in the mesocorticolimbic reward pathway following nicotine treatment. RNA was isolated from the indicated brain regions from animals treated with saline or nicotine as described in Materials and Methods. qRT-PCR was carried out for miR-494, miR-542-3p, $\mathrm{nAChR}$ a4, and nAChR $\beta 2$ transcripts as indicated. Student's $t$-test was used for statistical analysis, $\left(^{*}\right) P<0.05,\left({ }^{* *}\right) P<0.01 ; n=6$.

sequent immunoblotting. Transfection of the miR-542-3p mimic and inhibitor substantially increased $(\sim 640 \times$ control $)$ and decreased $(\sim 0.004 \times$ control $)$ miR-542-3p levels, respectively (data not shown). As shown in Figure 4, overexpression of miR-542-3p led to a statistically significant down-regulation of endogenous $\beta 2 \mathrm{nAChR}$ subunit expression. As a 


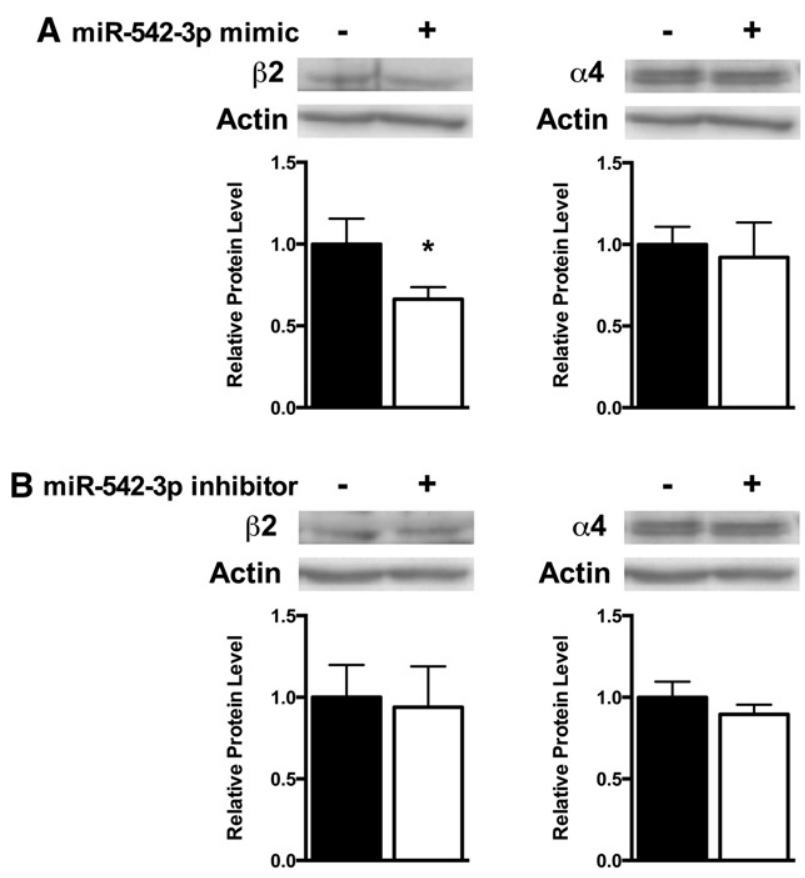

FIGURE 4. Over-expression of miR-542-3p down-regulates endogenous nAChR $\beta 2$ protein levels in differentiated PC12 cells. PC12 cells were transfected with miR-542-3p mimic $(A)$ or inhibitor $(B)$ and treated with NGF for $3 \mathrm{~d}$. Controls were transfected with control mimic or control inhibitor. Proteins were isolated and expression levels were analyzed by immunoblotting. Representative blots showing nAChR subunits and $\beta$-actin loading controls are presented above the corresponding graph. Each graph presents the average quantification of $n A C h R$ subunit protein levels for each sample, normalized to the $\beta$-actin loading control. Protein levels of miRNA mimic/inhibitor treated cells $(+)$ are presented relative to control mimic/inhibitor $(-)$. Student's $t$-test was used for statistical analysis, $\left(^{*}\right) P<0.05 ; n=4$.

negative control, a4 subunit expression was measured. The a4 gene does not contain any known miR-542-3p MREs, and as expected, there was no effect of miR-542-3p over-expression on a4 subunit levels (Fig. 4A). Somewhat puzzling was the lack of an effect of inhibiting miR-542-3p levels on nAChR expression (Fig. 4B). It may be that endogenous levels of miR-542-3p are below a certain threshold required for effects on $\mathrm{nAChR}$ expression and therefore, further lowering those levels with an inhibitor would produce no effect on receptor expression, an idea that needs to be tested in future studies.

In summary, we performed a large-scale miRNAome analysis of the mammalian neuronal $\mathrm{nAChR}$ family and have identified 27 miRNAs as potential regulators of nicotinic receptor expression. We identified MREs in the nAChR $3^{\prime}$ UTRs that are required for regulation by 14 of the miRNAs. Furthermore, expression of the majority of the candidate miRNAs is down-regulated by chronic nicotine treatment, consistent with a role in nicotine-induced nAChR up-regulation in the brain. Importantly, data are presented indicating a reciprocal relationship between miR-542-3p and $n A C h R$ $\beta 2$ mRNA expression in the mesocorticolimbic pathway fol- lowing nicotine treatment. Finally, overexpression of miR542-3p in differentiated PC12 cells led to a statistically significant decrease in $\beta 2$ subunit expression. To the best of our knowledge, this is the first such analysis of the nAChR family and sets the stage for further studies aimed at a variety of signaling pathways in which the receptors are involved.

An important next step is to extend the study of miRNA regulation of $\mathrm{nAChR}$ expression in vivo and to determine if that regulation impacts behavior. Indeed, recent reports have demonstrated that miRNAs are key regulatory factors in cocaine reinforcement (Hollander et al. 2010; Im et al. 2010) and alcohol tolerance (Pietrzykowski et al. 2008). It is also important to determine the precise spatial and temporal expression patterns of the miRNAs as this will have bearing on the molecular mechanisms underlying endogenous effects of miRNA regulation of $\mathrm{nAChR}$ expression. Given the broad array of diseases in which compromised cholinergic signaling is implicated (e.g., Alzheimer's disease, schizophrenia, nicotine addiction, etc.), our identification of a novel level of regulation of nicotinic receptor expression is likely to lead to unique therapeutic targets.

\section{MATERIALS AND METHODS}

\section{Bioinformatics}

Potential miRNA binding sites were identified using Targetscan (www.targetscan.org), Microcosm Targets (http://www.ebi.ac.uk/ enright-srv/microcosm/htdocs/targets/v5), and mirDIP (http://oph id.utoronto.ca/mirDIP/index.jsp). A miRbase Basic Local Alignment Search Tool was used to investigate homologous miRNAs between mouse and human (http://www.mirbase.org/search.shtml). Multiple Sequence Alignment (MUSCLE) was used to align mouse and human miRNA binding sites (http://www.ebi.ac.uk/Tools/msa/ muscle/).

\section{Cloning}

The $3^{\prime}$ UTRs of the nAChR subunits were amplified from mouse genomic DNA and cloned into the luciferase expression reporter vector, pMIR-REPORT Luciferase (Applied Biosystems). The wild-type a2 3'-UTR luciferase expression construct was generated by amplifying a 2063-bp SpeI/MluI fragment using forward primer: ACTA GTCCAGGTGAAGGAAGATTGGA and reverse primer: ACGCG TCTGGAGGGGACGAGTTAATG. The wild-type a3 3'-UTR luciferase expression construct was generated by amplifying a 1655-bp NaeI/HindIII fragment using forward primer: TATCTAGCCGG CCCCTTCTCCTTCATGTTCCA and reverse primer: ACGCGT CTGGAGGGGACGAGTTAATG. The wild-type a 4 3'-UTR luciferase expression construct was generated by amplifying a 2662-bp SpeI/HindIII fragment using forward primer: TGCTTTACTAGT CTGTGTTTGCAGGTGAAGGA and reverse primer: TCAGTTAA GCTTACACATGCCCACAGAGATGA. The wild-type a5 3'-UTR luciferase expression construct was generated by amplifying a 1159-bp SacI/PmeI fragment using forward primer: ACTTGGAG CTCACGCTAGGGCTTTTTGTTCC and reverse primer: AGGC GGTTTAAACGAATATGGACAAGGCGACTGA. The wild-type 
a6 3'-UTR luciferase expression construct was generated by amplifying a 2063-bp SpeI/HindIII fragment using forward primer: TGTCGTACTAGTGGCAGGCAAACATAATAGCA and reverse primer: CAGACTAAGCTTCCCACTCGGAAAAAGAAATG. The wild-type $a 73^{\prime}$-UTR luciferase expression construct was generated by amplifying a 672-bp SacI/HindIII fragment using forward primer: ATCCAGGAGCTCTGCAGTGAGTGGAAGTTTGC and reverse primer: ATTCATAAGCTTGACCAACTTTCTCCCTGGTG. The wild-type a9 3'-UTR luciferase expression construct was generated by amplifying a 850-bp SpeI/HindIII fragment using forward primer: GCCTGAACTAGTAAGGTCGCCAAGGTCATAGA and reverse primer: TAACTGAAGCTTGGCCAGGACAAAATCTTGAA. The wild-type a 10 3'-UTR luciferase expression construct was generated by amplifying a 852-bp SpeI/MluI fragment using forward primer: ATCCAGACTAGTCTCCTGGTACTGGTGCAAGC and reverse primer: ATAATAACGCGTCCCAACTTCTGGTTGTAGGC. Due to difficulty in amplifying the entire $\beta 23^{\prime}$ UTR as a single fragment, the $3^{\prime}$ UTR was amplified as two overlapping fragments, which were used to generate two separate luciferase- $\beta 23^{\prime}$-UTR constructs $(\beta 2.1$ and $\beta 2.2$ ). The wild-type $\beta 2.13^{\prime}$-UTR luciferase expression construct was generated by amplifying a 2042-bp NaeI/HindIII fragment using forward primer: ATAATAGCCGGCCCAGAACTAC ACTGCCACGA and reverse primer: TGAGACAAGCTTTCTT GGGGAACAATTCAGAGA. The wild-type $\beta 2.2$ 3'-UTR luciferase expression construct was generated by amplifying a 1939-bp SacI/ HindIII fragment using forward primer: ATACTGAGCTCGGCC ACTGTGCCTATGCTAT and reverse primer: TATAATAAGCTT CCCTCCCTCTGTCCCTTTAC. The wild-type $\beta 3$ 3'-UTR luciferase expression construct was generated by amplifying a 3205-bp NaeI/MluI fragment using forward primer: ATTATTGCCGGCC AGGTTCTTGACCGCATCTT and reverse primer: ACTTACAC GCGTCCCTCTCTCCACCCATAAGA. The wild-type $\beta 4$ 3'-UTR luciferase expression construct was generated by amplifying a 2354-bp MluI/PmeI fragment using forward primer: ATCCAGAC TAGTCTCCTGGTACTGGTGCAAGC and reverse primer: ATAA TAACGCGTCCCAACTTCTGGTTGTAGGC. For each amplification, mouse genomic DNA was mixed with an excess of the primers, dNTPs, reaction buffer and Phusion High-Fidelity DNA Polymerase (New England Biolabs). PCR steps generally included a 1-min initial denaturing step at $98^{\circ} \mathrm{C}$ and 35 cycles of the following: a $10-\sec 98^{\circ} \mathrm{C}$ melting step, a $30-\sec 72^{\circ} \mathrm{C}$ annealing step, and a $30-\sec 72^{\circ} \mathrm{C}$ extension step. The cycles were followed by a $5-\min 72^{\circ} \mathrm{C}$ final extension step. These parameters were altered slightly based on the primer melting temperatures. The PCR products were run on a DNA agarose gel and purified by a commercially available kit (QIAquick Gel Extraction Kit, Qiagen). Restriction enzyme digest and ligation reactions were accomplished using enzymes and buffers from New England Biolabs. Ligation products were transformed into competent Escherichia coli DH5a (Invitrogen) and grown in LB. Plasmids were isolated for transfection using a commercially available kit (Plasmid Maxi Prep, Qiagen). The 3'-UTR luciferase expression constructs were verified by nucleotide sequencing.

\section{Tissue culture and transfection}

HEK293T cells were grown in Dulbecco's modified Eagle's medium (DMEM, Mediatech) supplemented with 10\% fetal bovine serum. The cells were seeded at a density of 8000 cells per well into 96well plates. After $12 \mathrm{~h}$, the medium was changed to Opti-MEM and the HEK293T cells were transfected in triplicate with a pmiR-
REPORT Luciferase construct (20 ng) and a pmiR-REPORT- $\beta$-gal Control plasmid (20 ng) (Applied Biosystems) along with miRNA precursor mimics $(10 \mathrm{nM})$ from Pre-miR miRNA Precursor Library-Mouse V3 (Ambion). Each experiment included two negative control miRNA precursor mimics (Ambion). The plasmids and precursor mimics were introduced into the cells by liposome-mediated transfection using $1 \mu \mathrm{L}$ of Lipofectamine2000 (Invitrogen) per well. Twenty-four hours post-transfection, the cells were harvested, lysed, and assayed for luciferase activity using a commercially available kit (Promega Corp.) and a Lumimark Microplate Luminometer (Bio-Rad). To correct for differences in transfection efficiencies, luciferase activity in each sample was normalized to the $\beta$-galactosidase activity in that same sample. $\beta$-Galactosidase activity was measured using a commercially available kit (Galacto-Light; Tropix, Inc.). Student's $t$-test was used for statistical analysis.

PC12 cells were grown in DMEM supplemented with 10\% FBS and $5 \%$ heat-inactivated horse serum. Cells (passage 3-10) were seeded at a density of 400,000 cells per $60-\mathrm{mm}$ culture dish. After $24 \mathrm{~h}$, medium was changed to Opti-MEM and the cells were transfected in duplicate with 250 pmol of microRNA mimics or inhibitors for miR-494 (mirVana, Ambion) or miR-542-3p (miRIDIAN, Thermo), using $5 \mu \mathrm{L}$ of Lipofectamine Reagent (Invitrogen) per dish. After $24 \mathrm{~h}$, the medium was changed to growth medium containing $100 \mathrm{ng} / \mathrm{mL}$ nerve growth factor (NGF). After $48 \mathrm{~h}$, medium was exchanged with fresh growth medium containing NGF. Cells were harvested after an additional $24 \mathrm{~h}$ and total RNA was isolated using an RNAqueous Micro Kit (Ambion) for qRT-PCR and protein was isolated for Western blot as described below.

\section{Site-directed mutagenesis}

Site-directed mutagenesis of the nAChR subunit 3'-UTR luciferase constructs was accomplished by PCR site-directed mutagenesis using a commercially available kit (QuikChange Site-Directed Mutagenesis Kit, Stratagene). Two primers were designed per mutant. The $5^{\prime}$ primer was designed to substitute three to $4 \mathrm{nt}$ of the predicted miRNA binding sites. The $3^{\prime}$-UTR luciferase constructs were mixed with an excess of the primers, dNTPs, reaction buffer, and Pfu DNA polymerase for PCR. Since the parental DNA is isolated from E. coli and is therefore methylated, Dpn I was added to digest all methylated parental DNA. The mutated plasmids were transformed into competent E. coli XL1-Blue (Invitrogen), grown in LB and isolated by Plasmid Mini Prep (Qiagen). They were then transformed into competent E. coli $\mathrm{DH} 5 \alpha$ and grown in LB. Plasmids were isolated for transfection using a commercially available kit (Plasmid Maxi Prep, Qiagen). Mutations were verified by nucleotide sequencing.

\section{Animals}

Adult male C57BL/6J mice (Jackson Laboratory, West Grove, PA, USA) were used in the experiments. Mice were anesthetized by an intraperitoneal injection of a ketamine/xylazine solution $(0.1 \mathrm{~mL} /$ $10 \mathrm{~g}$ body weight, $10 \mathrm{mg} / \mathrm{mL}$ ketamine, $1 \mathrm{mg} / \mathrm{mL}$ xylazine). Osmotic minipumps (Alzet) containing saline or nicotine hydrogen tartrate solutions were implanted subcutaneously. Mice received a dose of $24 \mathrm{mg} / \mathrm{kg} / \mathrm{d}$ (nicotine base) for 20-24 d. Mice were culled by cervical dislocation followed by decapitation after which the brains were quickly dissected. All experiments were conducted in accordance with the guidelines for care and use of laboratory animals provided 
by the National Research Council (2010) as well as with an approved animal protocol from the Institutional Animal Care and Use Committee of the University of Massachusetts Medical School.

\section{Quantitative reverse transcription-polymerase chain reactions}

For whole-brain experiments (Supplemental Fig. 2), total RNA was isolated using a mirVana Kit (Ambion). For region-specific experiments (Fig. 3), brains were removed and placed on glass slides and snap-frozen in liquid nitrogen. Serial coronal sections $(1 \mathrm{~mm})$ were prepared and the PFC, NAc, and VTA were isolated using tissue punches (Harris UNI-CORE, $1.0 \mathrm{~mm}$; Electron Microscopy Sciences). Total RNA was isolated from the samples using a Micro Scale RNA Isolation Kit (Ambion). miRNAs were reverse-transcribed using a miRNA TaqMan Reverse Transcription Kit (Applied Biosystems). Quantitative reverse transcription-polymerase chain reactions (qRT-PCR) were done using an Applied Biosystems 7500 Real-Time System and miRNA TaqMan assays (Applied Biosystems). Samples containing no reverse transcriptase were used as negative controls. Relative gene expression was calculated using the $2^{-\Delta \Delta \mathrm{Ct}}$ method (Livak and Schmittgen 2001). Expression values are relative to sno202, a small nucleolar RNA not regulated by nicotine. Samples were analyzed in triplicate. Student's $t$-test was used for statistical analysis.

\section{Immunoblotting}

PC12 cells were grown and transfected as described above. Cells were washed twice in cold phosphate-buffered saline (PBS) and pelleted by centrifugation. To isolate proteins, cells were resuspended in 150-200 $\mu \mathrm{L}$ RIPA buffer (50 mM Tris-HCl pH 7.4, 150 mM NaCl, 1\% NP-40, $0.5 \%$ sodium deoxycholate, $0.1 \%$ SDS; Boston Bioproducts) supplemented with protease (Complete, EDTA-free; Roche) and phosphatase (Phos-Stop; Roche) inhibitors. After rotating for $1 \mathrm{~h}$ at $4^{\circ} \mathrm{C}$, cell debris was pelleted by centrifugation at $13,000 \mathrm{~g}$ for $30 \mathrm{~min}$ at $4^{\circ} \mathrm{C}$. The supernatant was removed and stored at $-80^{\circ} \mathrm{C}$. Protein concentration was determined by Bradford Assay. Protein $(40 \mu \mathrm{g})$ was added to reducing SDS-sample buffer (375 mM Tris $\mathrm{HCl}$ pH 6.8, 9\% SDS, 50\% glycerol, $9 \% \beta$-mercaptoethanol, $0.03 \%$ bromophenol blue; Boston Bioproducts) and boiled for $2 \mathrm{~min}$. Protein samples were then separated by $8 \%$ SDS-PAGE and electroblotted onto nitrocellulose membranes in transfer buffer ( $25 \mathrm{mM}$ Tris, $192 \mathrm{mM}$ glycine, $20 \%$ methanol). Membranes were blocked in 5\% nonfat dry milk (Blotting grade nonfat dry milk; Bio-Rad) in PBS with Tween-20 (PBST) for $1 \mathrm{~h}$ at room temperature. Membranes were cut just below $50 \mathrm{kDa}$ and the upper half was incubated with $1 \mu \mathrm{g} / \mathrm{mL}$ anti-AChR $\alpha 4$ (sc-5591; Santa Cruz) or anti-AChR $\beta 2$ (sc-11372; Santa Cruz) in blocking solution overnight at $4^{\circ} \mathrm{C}$. These antibodies were used based on their successful use as reported by others (Kabbani et al. 2007; Wecker et al. 2010; Shimizu et al. 2011). As loading control, $\beta$-actin was detected in the lower half of the membrane using $1 \mu \mathrm{g} / \mathrm{mL}$ anti-actin antibody (sc-56459; Santa Cruz) in blocking solution. Blots were incubated in HRP-linked secondary antibody for the anti-AChR $(0.8 \mu \mathrm{g} / \mathrm{mL}$, sc-2020; Santa Cruz) or anti-actin antibodies ( $5 \mathrm{ng} / \mathrm{mL}$ Cat\# 32430; Thermo) for $1.5 \mathrm{~h}$ at room temperature. After application of SuperSignal West Dura Chemiluminescent Substrate (Thermo) to the blots, proteins were visualized using a VersaDoc MP 5000 Imaging System (Bio-Rad) at various exposure times.
Membranes were stripped using Restore Western Blot Stripping Buffer (Thermo) for detection of the other nAChR subunit. Protein band intensity was quantified using ImageJ software and the $\mathrm{nAChR}$ subunit protein levels for each sample were normalized to the $\beta$-actin loading control. Protein levels of miRNA mimic- or inhibitor-treated cells are presented relative to controls. Student's $t$-test was used for statistical analysis.

\section{SUPPLEMENTAL MATERIAL}

Supplemental material is available for this article.

\section{ACKNOWLEDGMENTS}

This paper is dedicated to the memory of E.M.H. We thank Phil Zamore, Thoru Pederson, and Dave Weaver as well as the members of the Gardner/Tapper laboratory and our colleagues at the BNRI, UMassMed and NIDA for their advice and support. We thank Xueyan Pang for her help with the Western blots. This work was supported by generous donations to the Eric M. Hogan Memorial Fund and by Grant Number F31DA029386 from the National Institute of Drug Abuse (National Institutes of Health) to E.M.H. and from the National Institute of Drug Abuse Grants Number R21DA033543 to P.D.G. and Number R21DA031952 to P.D.G. and A.R.T. The content is solely the responsibility of the authors and does not necessarily represent the official views of the National Institute of Drug Abuse or the National Institutes of Health.

Received August 15, 2014; accepted September 5, 2014.

\section{REFERENCES}

Albuquerque EX, Pereira EF, Alkondon M, Rogers SW. 2009. Mammalian nicotinic acetylcholine receptors: from structure to function. Physiol Rev 89: 73-120.

Ambros V. 2004. The functions of animal microRNAs. Nature 431: 350-355.

Ameres SL, Zamore PD. 2013. Diversifying microRNA sequence and function. Nat Rev Mol Cell Biol 14: 475-488.

Balaraman S, Winzer-Serhan UH, Miranda RC. 2012. Opposing actions of ethanol and nicotine on microRNAs are mediated by nicotinic acetylcholine receptors in fetal cerebral cortical-derived neural progenitor cells. Alcohol Clin Exp Res 36: 1669-1677.

Bartel DP. 2009. MicroRNAs: target recognition and regulatory functions. Cell 136: 215-233.

Benwell ME, Balfour DJ, Anderson JM. 1988. Evidence that tobacco smoking increases the density of $(-)-\left[{ }^{3} \mathrm{H}\right]$ nicotine binding sites in human brain. J Neurochem 50: 1243-1247.

Bicker S, Schratt G. 2008. microRNAs: tiny regulators of synapse function in development and disease. J Cell Mol Med 12: 1466-1476.

Cao X, Yeo G, Muotri AR, Kuwabara T, Gage FH. 2006. Noncoding RNAs in the mammalian central nervous system. Annu Rev Neurosci 29: 77-103.

Coe JW, Brooks PR, Vetelino MG, Wirtz MC, Arnold EP, Huang J, Sands SB, Davis TI, Lebel LA, Fox CB, et al. 2005. Varenicline: an a $4 \beta 2$ nicotinic receptor partial agonist for smoking cessation. $J$ Med Chem 48: 3474-3477.

Columbo SF, Mazzo F, Pistillo F, Gotti C. 2013. Biogenesis, trafficking and up-regulation of nicotinic ACh receptors. Biochem Pharmacol 86: 1063-1073.

Cooper E, Couturier S, Ballivet M. 1991. Pentameric structure and subunit stoichiometry of a neuronal nicotinic acetylcholine receptor. Nature 350: 235-238. 
Corringer PJ, Le Novère N, Changeux JP. 2000. Nicotinic receptors at the amino acid level. Annu Rev Pharmacol Toxicol 40: 431-458.

Dani JA. 1993. Structure, diversity, and ionic permeability of neuronal and muscle acetylcholine receptors. EXS 66: 47-59.

Dani JA. 2001. Overview of nicotinic receptors and their roles in the central nervous system. Biol Psychiatry 49: 166-174.

Darsow T, Booker TK, Piña-Crespo JC, Heinemann SF. 2005. Exocytic trafficking is required for nicotine-induced up-regulation of $\alpha 4 \beta 2$ nicotinic acetylcholine receptors. J Biol Chem 280: 18311-18320.

Ficklin MB, Zhao S, Feng G. 2005. Ubiquilin-1 regulates nicotine-induced up-regulation of neuronal nicotinic acetylcholine receptors. J Biol Chem 280: 34088-34095.

Fiore R, Siegel G, Schratt G. 2008. MicroRNA function in neuronal development, plasticity and disease. Biochim Biophys Acta 1779: 471-478.

Flores CM, Rogers SW, Pabreza LA, Wolfe BB, Kellar KJ. 1992. A subtype of nicotinic cholinergic receptor in rat brain is composed of a4 and $\beta 2$ subunits and is up-regulated by chronic nicotine treatment. Mol Pharmacol 41: 31-37.

Friedman RC, Farh KK, Burge CB, Bartel DP. 2009. Most mammalian mRNAs are conserved targets of microRNAs. Genome Res 19: 92-105.

Gallego X, Cox RJ, Laughlin JR, Stitzel JA, Ehringer MA. 2013. Alternative CHRNB4 $3^{\prime}$-UTRs mediate the allelic effects of SNP rs1948 on gene expression. PLoS One 8: e63699.

Ghildiyal M, Zamore PD. 2009. Small silencing RNAs: an expanding universe. Nat Rev Genet 10: 94-108.

Govind AP, Vezina P, Green WN. 2009. Nicotine-induced upregulation of nicotinic receptors: underlying mechanisms and relevance to nicotine addiction. Biochem Pharmacol 78: 756-765.

Govind AP, Walsh H, Green WN. 2012. Nicotine-induced upregulation of native neuronal nicotinic receptors is caused by multiple mechanisms. J Neurosci 32: 2227-2238.

Griffiths-Jones S, Saini HK, van Dongen S, Enright AJ. 2008. miRBase: tools for microRNA genomics. Nucleic Acids Res 36: D154-D158.

Ha M, Kim VN. 2014. Regulation of microRNA biogenesis. Nat Rev Mol Cell Biol 15: 509-524.

Henderson LP, Gdovin MJ, Liu C, Gardner PD, Maue RA. 1994. Nerve growth factor increases nicotinic $\mathrm{ACh}$ receptor gene expression and current density in wild-type and protein kinase A-deficient PC12 cells. J Neurosci 14: 1153-1163.

Hollander JA, Im HI, Amelio AL, Kocerha J, Bali P, Lu Q, Willoughby D, Wahlestedt C, Conkright MD, Kenny PJ. 2010. Striatal microRNA controls cocaine intake through CREB signalling. Nature 466: 197-202.

Huang W, Li MD. 2009. Nicotine modulates expression of miR-140*, which targets the $3^{\prime}$-untranslated region of dynamin 1 gene (Dnm1). Int J Neuropsychopharmacol 12: 537-546.

Im H, Hollander JA, Bali P, Kenny PJ. 2010. MeCP2 controls BDNF expression and cocaine intake through homeostatic interactions with microRNA-212. Nat Neurosci 13: 1120-1127.

Improgo MR, Scofield MD, Tapper AR, Gardner PD. 2010. From smoking to lung cancer: the CHRNA5/A3/B4 connection. Oncogene 29: 4874-4884.

Izzotti A, Calin GA, Arrigo P, Steele VE, Croce CM, De Flora S. 2009. Downregulation of microRNA expression in the lungs of rats exposed to cigarette smoke. FASEB J 23: 806-812.

Kabbani N, Woll MP, Levenson R, Lindstrom JM, Changeux JP. 2007. Intracellular complexes of the $\beta 2$ subunit of the nicotinic acetylcholine receptor in brain identified by proteomics. Proc Natl Acad Sci 104: 20570-20575.

Leonard S, Bertrand D. 2001. Neuronal nicotinic receptors: from structure to function. Nicotine Tob Res 3: 203-223.

Lewis BP, Burge CB, Bartel DP. 2005. Conserved seed pairing, often flanked by adenosines, indicates that thousands of human genes are microRNA targets. Cell 120: 15-20.

Lippi G, Steinert JR, Marczylo EL, D’Oro S, Fiore R, Forsythe ID, Schratt G, Zoli M, Nicotera P, Young KW. 2011. Targeting of the Arpc 3 actin nucleation factor by $\mathrm{miR}-29 \mathrm{a} / \mathrm{b}$ regulates dendritic spine morphology. J Cell Biol 194: 889-904.
Livak KJ, Schmittgen TD. 2001. Analysis of relative gene expression data using real-time quantitative PCR and the $2^{-\Delta \Delta \mathrm{CT}}$ Method. Methods 25: 402-408.

Marks MJ, Burch JB, Collins AC. 1983. Effects of chronic nicotine infusion on tolerance development and nicotinic receptors. J Pharmacol Exp Ther 226: 817-825.

Marks MJ, Pauly JR, Gross SD, Deneris ES, Hermans-Borgmeyer I, Heinemann SF, Collins AC. 1992. Nicotine binding and nicotinic receptor subunit RNA after chronic nicotine treatment. J Neurosci 12: 2765-2784.

McGehee DS, Role LW. 1995. Physiological diversity of nicotinic acetylcholine receptors expressed by vertebrate neurons. Annu Rev Physiol 57: 521-546.

Moroni M, Zwart R, Sher E, Cassels BK, Bermudez I. 2006. $\alpha 4 \beta 2$ Nicotinic receptors with high and low acetylcholine sensitivity: pharmacology, stoichiometry, and sensitivity to long-term exposure to nicotine. Mol Pharmacol 70: 755-768.

Nashmi R, Dickinson ME, McKinney S, Jareb M, Labarca C, Fraser SE, Lester HA. 2003. Assembly of $\alpha 4 \beta 2$ nicotinic acetylcholine receptors assessed with functional fluorescently labeled subunits: effects of localization, trafficking, and nicotine-induced upregulation in clonal mammalian cells and in cultured midbrain neurons. J Neurosci 23: 11554-11567.

Nelson ME, Kuryatov A, Choi CH, Zhou Y, Lindstrom J. 2003. Alternate stoichiometries of $\alpha 4 \beta 2$ nicotinic acetylcholine receptors. Mol Pharmacol 63: 332-341.

Peng X, Gerzanich V, Anand R, Whiting PJ, Lindtrom J. 1994. Nicotineinduced increase in neuronal nicotinic receptors results from a decrease in the rate of receptor turnover. Mol Pharmacol 46: 523-530.

Picciotto MR, Zoli M, Rimondini R, Léna C, Marubio LM, Pich EM, Fuxe K, Changeux JP. 1998. Acetylcholine receptors containing the $\beta 2$ subunit are involved in the reinforcing properties of nicotine. Nature 391: 173-177.

Pietrzykowski AZ, Friesen RM, Martin GE, Puig SI, Nowak CL, Wynne PM, Siegelmann HT, Treistman SN. 2008. Posttranscriptional regulation of BK channel splice variant stability by miR-9 underlies neuroadaptation to alcohol. Neuron 59: 274-287.

Rezvani K, Teng Y, Shim D, De Biasi M. 2007. Nicotine regulates multiple synaptic proteins by inhibiting proteasomal activity. J Neurosci 27: 10508-10519.

Salas R, Sturm R, Boulter J, De Biasi M. 2009. Nicotinic receptors in the habenulo-interpeduncular system are necessary for nicotine withdrawal in mice. J Neurosci 29: 3014-3018.

Sallette J, Pons S, Devillers-Thiery A, Soudant M, Prado de Carvalho L, Changeux JP, Corringer PJ. 2005. Nicotine upregulates its own receptors through enhanced intracellular maturation. Neuron 46: 595-607.

Salmena L, Poliseno L, Tay Y, Kats L, Pandolfi PP. 2011. A ceRNA hypothesis: the Rosetta Stone of a hidden RNA language? Cell 146: 353-358.

Schembri F, Sridhar S, Perdomo C, Gustafson AM, Zhang X, Ergun A, Lu J, Liu G, Zhang X, Bowers J, et al. 2009. MicroRNAs as modulators of smoking-induced gene expression changes in human airway epithelium. Proc Natl Acad Sci 107: 2319-2324.

Shan H, Zhang Y, Lu Y, Zhang Y, Pan Z, Cai B, Wang N, Li X, Feng T, Hong Y, et al. 2009. Downregulation of miR-133 and miR-590 contributes to nicotine-induced atrial remodelling in canines. Cardiovasc Res 83: 465-472.

Shimizu T, Tanaka K, Hasegawa T, Yokotani K. 2011. Brain a4ß2 nicotinic acetylcholine receptors are involved in the secretion of noradrenaline and adrenaline from adrenal medulla in rats. Eur $J$ Pharmacol 654: 241-248.

Shirdel EA, Xie W, Mak TW, Jurisica I. 2011. NAViGaTing the micronome-using multiple microRNA prediction databases to identify signalling pathway-associated microRNAs. PLoS One 6: e17429.

Simon DJ, Madison JM, Conery AL, Thompson-Peer KL, Soskis M, Ruvkun GB, Kaplan JM, Kim JK. 2008. The microRNA miR-1 
regulates a MEF-2-dependent retrograde signal at neuromuscular junctions. Cell 133: 903-915.

Srinivasan R, Pantoja R, Moss FJ, Mackey ED, Son CD, Miwa J, Lester HA. 2011. Nicotine up-regulates $\alpha 4 \beta 2$ nicotinic receptors and ER exit sites via stoichiometry-dependent chaperoning. J Gen Physiol 137: 59-79.

Tapper AR, McKinney SL, Nashmi R, Schwarz J, Deshpande P, Labarca C, Whiteaker P, Marks MJ, Collins AC, Lester HA. 2004. Nicotine activation of $\alpha 4^{*}$ receptors: sufficient for reward, tolerance, and sensitization. Science 306: 1029-1032.

Thomas M, Lieberman J, Lal A. 2010. Desperately seeking microRNA targets. Nat Struct Mol Biol 17: 1169-1174.

Vallejo YF, Buisson B, Bertrand D, Green WN. 2005. Chronic nicotine exposure upregulates nicotinic receptors by a novel mechanism. J Neurosci 25: 5563-5572.

Vasudevan S, Tong Y, Steitz JA. 2007. Switching from repression to activation: microRNAs can up-regulate translation. Science 318: 1931-1934.
Walsh H, Govind AP, Mastro R, Hoda JC, Bertrand D, Vallejo Y, Green WN. 2008. Up-regulation of nicotinic receptors by nicotine varies with receptor subtype. J Biol Chem 283: 6022-6032.

Wecker L, Pollock VV, Pacheco MA, Pastoor T. 2010. Nicotine-induced up regulation of $\alpha 4 \beta 2$ neuronal nicotinic receptors is mediated by the protein kinase C-dependent phosphorylation of a4 subunits. Neuroscience 171: 12-22.

WHO. 2009. WHO report on the global tobacco epidemic, 2009: implementing smoke-free environments. World Health Organization.

Zhao-Shea R, Liu L, Soll LG, Improgo MR, Meyers EE, McIntosh JM, Grady SR, Marks MJ, Gardner PD, Tapper AR. 2011. Nicotinemediated activation of dopaminergic neurons in distinct regions of the ventral tegmental area. Neuropsychopharmacology 36: 10211032.

Zhao-Shea R, Liu L, Pang X, Gardner PD, Tapper AR. 2013. Activation of GABAergic neurons in the interpeduncular nucleus triggers physical nicotine withdrawal symptoms. Curr Biol 23: 2327-2335. 

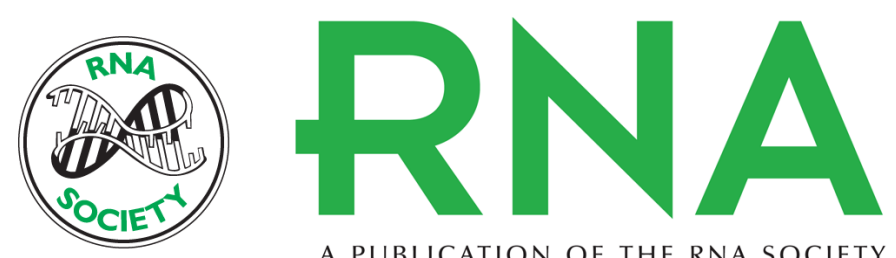

A PUBLICATION OF THE RNA SOCIETY

\section{miRNAome analysis of the mammalian neuronal nicotinic acetylcholine receptor gene family}

Eric M. Hogan, Alison P. Casserly, Michael D. Scofield, et al.

RNA 2014 20: 1890-1899 originally published online October 24, 2014

Access the most recent version at doi:10.1261/rna.034066.112

\section{Supplemental http://rnajournal.cshlp.org/content/suppl/2014/10/06/rna.034066.112.DC1 Material}

References This article cites 63 articles, 21 of which can be accessed free at: http://rnajournal.cshlp.org/content/20/12/1890.full.html\#ref-list-1

Creative This article is distributed exclusively by the RNA Society for the first 12 months after the Commons License full-issue publication date (see http://rnajournal.cshlp.org/site/misc/terms.xhtml). After 12 months, it is available under a Creative Commons License (Attribution-NonCommercial 4.0 International), as described at http://creativecommons.org/licenses/by-nc/4.0/.

Email Alerting
Service

Receive free email alerts when new articles cite this article - sign up in the box at the top right corner of the article or click here.

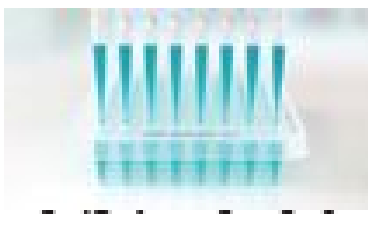

Providing Precise Solutions for your research.

To subscribe to $R N A$ go to:

http://rnajournal.cshlp.org/subscriptions 